\title{
EDUARDO MUJICA CON UNIVERSIDAD CATÓLICA DE CHILE -CORPORACIÓN DE TELEVISIÓN-.
}

\author{
PAULO ROMÁN \\ Abogado
}

1. El fallo que se comenta es fiel a los vicios que se advierten en otros, tanto de la Excma. Corte Suprema, de Apelaciones y tribunales de primera instancia, y en los cuales se considera a la doctrina de los actos propios al momento de resolver el conflicto planteado: referencias superficiales, arbitrarias y no fundamentadas, que suman densidad al velo de duda que rodea la aplicación de esta teoría:

Si las referencias a los propios actos despiertan suspicacias en materia de derecho civil o administrativo, en sede laboral huelen a herejía. Se dice que su aplicación contradice y violenta los principios más caros a esta disciplina, como son, al menos, la irrenunciabilidad de los derechòs, la primacía de la realidad y la protección del trabajador.

No suscribimos esta tesis, por el contrario, la aplicación de la doctrina de los actos propios no solo nos parece procedente, sino que, y sobre todo, deseable, de cumplirse con ciertos requisitos básicos e imprescindibles.

2. Sin detenernos en los orígenes de esta teoría, podemos afirmar que hoy su aplicación tiene directa relación con el principio de buena fe, el cual informa, de principio a fin, a todo el ordenamiento jurídico.

En el mismo sentido, no nos parece lícito distinguir entre las distintas ramas del Derecho al momento de conjeturar acerca de la procedencia de esta doctrina, por cuanto la buena fe es transversal a todas ellas; en cambio, sí es lícito determinar de manera detallada, a la luz de cada especialidad, la forma en que esta teoría deberá ser aplicada, con el objeto de no entrar en contradicción con los principios propios de cada área específica.

Concordante con lo anterior, la aplicación al caso particular deberá ser estricta y razonada, considerando las particularidades propias de cada especialidad, pero, siempre, ateniéndose de manera precisa a los requisitos que, de manera general, ha aceptado la doctrina nacional y extranjera para la procedencia de la teoría de los actos propios. Estos requisitos son los siguientes: en primer lugar, el acto primero $u$ original debe ser lícito y eficaz -conducta vinculante-; en segundo término, se debe colegir, del posterior actuar contradictorio del agente, que se encuentra actuando de mala fe; $y$, por último, debe existir identidad entre las partes.

3. La sentencia que se comenta, corresponde a la de fecha 30 de agosto de 2006 , dictada por la Excma. Corte Suprema, en los autos rol N 981-2005, caratulado "Mujica Vargas, Eduardo con Universidad Católica de Chile Televisión -Corporación de Televisión-”, que resolvió el recurso de casación en la forma y fondo, interpuesto por el demandante de autos, don Eduardo Mujica, en contra de la sentencia de la Corte de Apelaciones de Santiago, de fecha 20 de enero de 2005, que, por su parte, revocó la sentencia de primera instancia. 
Paulo Román / Eduardo Mujica con Universidad Católica de Chile -Corporación de Televisión-

A su vez, la indicada sentencia de primera instancia corresponde al fallo de fecha 27 de marzo de 2004, mediante el cual el $4^{\circ}$ Juzgado del Trabajo de Santiago reconoció la existencia de una relación laboral entre demandante y demandado, en circunstancias que este último alegó la existencia de una relación de prestación de servicios civil, y no otra cosa, a pesar de haber prestados servicio durante 19 años, sin alegar vínculo alguno.

4. Tal como ya anunciáramos, la Corte Suprema de Justicia ha continuado la senda ya trazada por Cortes y tribunales de primera instancia, esto es, la referencia intuitiva y casi casual que se hace a la doctrina de los actos propios al citarla como fuente directa para la resolución del conflicto.

La única referencia explícita que se hace a la mentada doctrina en el fallo en asunto es la siguiente:

"[P] or otro lado, agrega que el tribunal de segunda instancia, manteniendo los hechos asentados por el de primera, los cuales, a su juicio, llevan lógicamente a acoger la demanda, emite la decisión contraria, infringiendo importante principios informadores del derecho laboral, como la primacía de la realidad, la irrenunciabilidad de los derechos y la protección del trabajador, atribuyéndole una conducta de mala fe mediante la aplicación de la doctrina de los actos propios...”.

La Corte Suprema, por lo tanto, nada dice acerca de cómo un hecho del demandante, esto es, el haber actuado durante 19 años comó un prestador de servicios civiles -su conducta vinculante-, es necesariamente contradictoria con su posterior demanda. Menos se refiere al hecho de haber obtenido eventuales devoluciones de impuesto, de haber gozado de un horario flexible, etc., todos ellos antecedentes que demuestran que el demandante operó bajo un régimen determinado, mientras le fue conveniente, para luego, cuando igualmente le convenía, desconocerlo. Tampoco, aunque sea para efectos de registro o puramente formales, indica que se cumple también con la identidad de las partes.

En consecuencia, tan escuálido fallo deja abiertos todos los flancos posibles para que sus férreos detractores hagan un festín con él.

En comentario a esta misma sentencia, y a la aplicación de la doctrina de los actos propios en materia laboral en general, Juan Sebastián Gumucio y Diego Corvera ${ }^{1}$ se muestran contrarios a la sola posibilidad de la aplicación de la teoría de los actos propios en materia laboral, por cuanto estiman que es ilusorio estimar que las partes del contrato se encuentran actuando en un nivel de igualdad y, asimismo, que es falso que la eventual simulación relativa existente entre las partes las afectaría solo a ellas.

Indican que el fallo no repara en un hecho por todos conocidos, cual es la notoria desigualdad existente entre empleador y trabajador, sobre todo en la fase de nacimiento y desarrollo del contrato, como así también que justifica una injusticia evidente, cual es que, pudiendo haber existido simulación entre empleador y trabajador, solo sanciona a este último.

\footnotetext{
${ }^{1}$ Gumucio Rrvas, Juan Sebastián y Corvera Vergara, Diego, “Comentarios a una Jurisprudencia: La Doctrina de los actos propios y el Derecho Laboral”, en: Revista Laboral Chilena, noviembre 2006.
} 
Lo anterior, sin considerar que, según indican, se estaría consolidando con este fallo un contrato nulo o simulado que afecta intereses de terceros, ya que el derecho laboral protege no solo al trabajador, sino que a la sociedad entera, por ser de orden público.

En definitiva, concluyen que:

"(1)a jurisprudencia comentada tiene una fundamentación que no puede tener cabida en el ámbito del Derecho del Trabajo. Sus consecuencias son incalculables, toda vez que a pretexto de la denominada doctrina de los actos propios, se deja sin aplicación el conjunto de las normas imperativas, quedando entregada a la voluntad de las partes regirse o no por sus disposiciones..."2.

Sin embargo, el análisis recién citado no se hace cargo de una posibilidad que, de tan evidente, suele obviarse: ¿cuál es el fundamento para impedir la celebración de un contrato de prestación de servicios civiles, entre dos partes que, originalmente de buena fe, consintieron en él?

Es acaso, motivo suficiente para ello, ¿la diferencia de fuerzas, principalmente patrimoniales, entre empleador y trabajador? $\mathrm{o}$, ¿el hecho que existan numerosos casos en que se ha cometido un abuso por parte del empleador, justifica establecer en base a ello una prohibición? ¿ No parece un razonamiento lógico suponer que las normas de orden público propias del Derecho del Trabajo, se aplican solo cuando estamos ante una relación laboral y no civil?

Siendo fieles a los hechos, debemos reconocer que, habitualmente, no habrá igualdad entre el futuro empleador y trabajador al momento de negociar o acordar las condiciones del contrato de trabajo. No obstante ello, la apreciada igualdad no es requisito indispensable para la celebración de un contrato de prestación de servicio civil, por cuanto, recurriendo a la casuística, casi cualquier relación de esta naturaleza estará atravesada por una irremediable diferencia de las fuerzas patrimoniales.

Evidentemente, la distinta fuerza de los patrimonios no impide que un trabajador, con conocimiento de la realidad de los hechos, decida, por conveniencia, falta de mejores oportunidades o arbitraria preferencia, prestar servicios a otro bajo un vínculo más tenue, como es el derivado de la prestación de servicios civiles.

En definitiva, creemos que en el centro del debate debe estar la libertad del individuo: la toma de una decisión, con conocimiento de los hechos, supone una opción legítima e incuestionable.

De acuerdo a lo ya expuesto, resulta medular para entender este problema y darle justa solución, hacerse cargo de la buena fe en la conducta desplegada por las partes del contrato.

Raimundo Opazo aporta un punto de vista interesante y fresco dentro de la doctrina laboral. En efecto, afirma:

${ }^{2}$ Ibid. 
“(s)e señala también, para refutar la procedencia de la doctrina de los actos propios en el ámbito laboral, que la parte empresarial estaría, bajo esta doctrina, ocultando, abusos y fraudes. El argumento puede estimarse válido solo cuando la conducta anterior relevante y eficaz no sea válida, lo que ocurrirá cuando la voluntad de uno de los contratantes no haya sido emitida voluntariamente o coaccionada. Si la conducta anterior fuese jurídicamente ilegítima, ella podría ser atacada sin que ello vulnere la doctrina de los actos propios...".

"...dicho de otra forma, es contrario a derecho, pugna con la lógica y es absurdo suponer que si ambos contratantes son partícipes de un acto 'simulado', uno de ellos pueda verse beneficiado con la declaración de ser trabajador dependiente desdiciéndose de su declaración de voluntad inicial y conducta ejecutada, impetrando una realidad distinta para aprovecharse de ella..."3.

Suscribimos lo expuesto, en cuanto nos parece de toda lógica lo señalado por Raimundo Opazo, ya que su razonamiento parte desde un punto habitualmente olvidado por el resto de la doctrina laboral: no tiene sentido negar lugar a la teoría de los propios actos en materia laboral, si el actuar del prestador de servicios fue legítimo y eficaz, es decir, si quien desplegó un comportamiento determinado lo hizo con conocimiento de lo que hacía y actuando en libertad, esto es, de buena fe.

Por otra parte, parece igualmente justo entender que, en el caso de la simulación, no puede beneficiarse ni a empleador ni a trabajador, por cuanto, como ya se indicó por parte de Gumucio y Corvera ${ }^{4}$, el derecho laboral no solo protege al trabajador sino que a la sociedad toda. Se escandalizan los citados autores por el supuesto beneficio que el acto simulado operaría en favor del empleador, pero nada dicen del injusto que se cometería de fallar en favor del trabajador -prestador de servicios, en términos estrictos-.

En resumen, podemos afirmar que el fallo de la Corte Suprema, no obstante que con los antecedentes citados nos parece resuelve de la manera correcta, incurre en los vicios repetidos una y otra vez por la misma Corte y tribunales de primera instancia, esto es, falta de rigor en el razonamiento jurídico, liviandad argumentativa y superficialidad teórica.

No podemos discutir que la práctica y el día a día dan cuenta de repetidos abusos por parte del empleador $-y$ no pocos del trabajador-, encubriendo muchas veces relaciones laborales bajo figuras civiles. Sin embargo, no es ello fundamento suficiente para establecer un criterio general y normativo, suponiendo siempre un actuar doloso del empleador.

El que los argumentos esgrimidos por la doctrina para el rechazo de la aplicación de esta teoría, supongan mala fe y abuso de posición dominante por parte del empleador, es una inconsistencia argumentativa mayor. Si los hechos dan cuenta de que las partes actuaron de buena fe y ateniéndose al derecho, la aplicación de esta doctrina es inobjetable.

\footnotetext{
${ }^{3}$ Opazo Mulack, Raimundo, "La Doctrina de los Actos Propios y su procedencia en la solución de los conflictos laborales", en: Estudios Laborales, N 4, p. 69. Santiago: LegalPublishing, 2009.

${ }^{4}$ Gumucio Rivas, Juan Sebastián y Corvera Vergara, Diego, op. cit. (n. 1).
} 